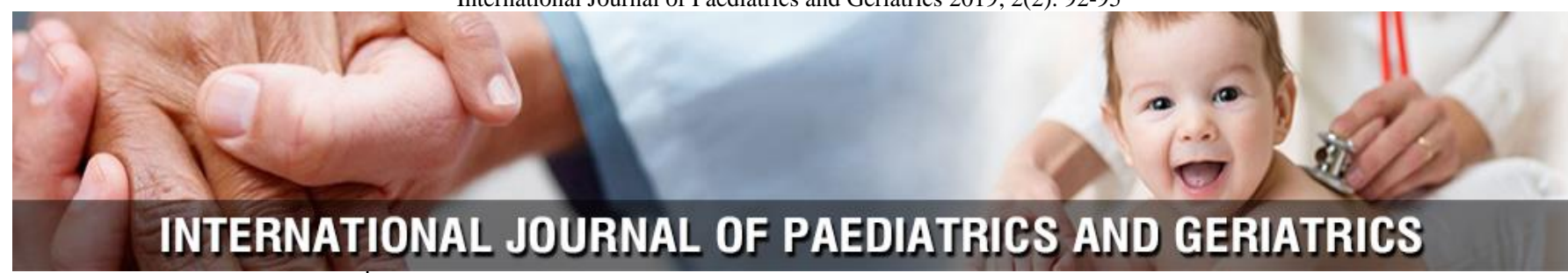

P-ISSN: 2664-3685

E-ISSN: 2664-3693

www.paediatricjournal.com

IJPG 2019; 2(2): 92-95

Received: 25-05-2019

Accepted: 28-06-2019

Dr. Mahesh Bhagavati

Assistant Professor,

Department of Pediatrics,

KIMS, Koppal, Karnataka,

India

Dr. Basavanthappa SP Professor and HOD,

Department of Pediatrics,

Basaveshwara Medical College,

Chitradurga, Karnataka, India

Dr. Pooja V

Resident, Department of

Pediatrics, Basaveshwara

Medical College, Chitradurga,

Karnataka, India
Corresponding Author: Dr. Basavanthappa SP Professor and HOD, Department of Pediatrics, Basaveshwara Medical College, Chitradurga, Karnataka, India

\section{A study on clinical profile of paediatric patients with dengue fever at a tertiary care hospital}

\author{
Dr. Mahesh Bhagavati, Dr. Basavanthappa SP and Dr. Pooja V
}

DOI: https://doi.org/10.33545/26643685.2019.v2.i2b.40

\begin{abstract}
Dengue fever is a major public health problem especially in Indian subcontinent. It is a mosquito borne arboviral infection which results in significant morbidity and mortality. The complications of dengue fever usually happen after the 5th day of illness which include fluid leak, bleeding, hepatitis, encephalopathy, ARDS. The studies on dengue in paediatric age group are scant in this part of the country. Cross sectional study was conducted on 250 pediatric cases presenting with fever for 2 to 7 days, presenting at OPD/IPD of pediatric department. This study had shown that, the age group was between $6-9$ years, males sex, fever was the common sign, hepatomegaly was the common sign, leucopenia, reduced platelet count, NS1 positive, IgM and IgG positive, normal C3 count, positive Widal test abnormal USG abdomen, more than 5 days of hospitalization and mortality was present in $11.1 \%$ of the cases.
\end{abstract}

Keywords: Dengue hemorrhagic fever, complications, laboratory investigations, mortality, pediatric patients

\section{Introduction}

Dengue fever is an internationally recognized major public health problem especially in tropical and subtropical countries mainly affecting urban and sub urban areas. It is a most common mosquito - borne arbo viral infection (single stranded RNA virus) which results in significant morbidity and mortality.

The dengue virus is capable of infecting humans and causing the disease. The estimates have shown that, 2.5 billion people are mainly living in urban areas who are under risk of acquiring the infection ${ }^{[1]}$. The literature available has shown that, the dengue is more common in more than 100 countries, most cases are reported mainly from South East Asia and western pacific regions ${ }^{[2]}$. There are about 50 and 100 million cases of dengue fever (DF) and about 500,000 cases of dengue hemorrhagic (DHF) each year which require hospitalization. It has become a leading cause of hospitalization and death especially among the children in the South - East Asia region of WHO over last 10 - 15 years following diarrhoea disease and acute respiratory infections ${ }^{[3]}$.

Dengue is a mosquito - borne disease caused by serologically related but antigenically distinct single strand positive RNA viruses. The literature available had shown that four different types of serotypes are known cause Dengue infection (DENV through DENV - 4. They belong to flavivirus family (Family flaviviridae). Aedes Aegypti is the primary mosquito vector but other species of genus Aedes, such as Aedes albopictus can also act as vector for the virus transmission. The clinical spectrum may range from asymptomatic infection, mild dengue fever (DF), dengue hemorrhagic fever (DHF) or dengue shock syndrome, which is often fatal because of abnormal capillary permeability and plasma leakage. The disease can also manifest in unusual manner resulting in myocardiopathy, hepatic failure and neurological disorders. Specific treatment for the dengue is not available till today but only vector control is the main preventive strategy ${ }^{[4]}$.

Plasma leakage due to alteration in microvascular permeability is the pathognomonic feature of the severe DHF. No vaccine and specific antiviral therapy for DF/DHF and management of cases remains largely supportive. The dengue virus is often confused with other febrile illness of viral origin which confounds both clinical management and disease surveillance for prevention of viral transmission. Non specific clinical symptoms predominate during the early phase of illness which makes the clinical management difficult. Retro-orbital pain and clinical signs including Petechiae are definitive symptom and sign which do not appear until 
the later stage of illness ${ }^{[5]}$. The diagnostic tests such as RTPCR is costly; not sufficiently rapid, such as virus isolation or under field trials including ELISA for NS1 protein of Dengue virus can be used at early stages of illness. Simple haematological or biochemical tests are the need of the hour which can be useful for case management and preventing mortality and morbidity ${ }^{[6]}$.

The radiological techniques including ultrasonography is useful in diagnosing GB wall thickening, pericholecystic fluid, minimal ascites, pleural effusion, pericardial effusion and hepatosplenomegaly. The ultrasonography was also able to find the abnormality of liver parenchyma which can be due to intraparenchymal and subcapsular haemorrhages. GB wall thickening in DF can be due to decrease in intravscualr osmotic pressure ${ }^{[7]}$.

The complications of dengue fever usually happen after the $5^{\text {th }}$ day of illness. The complications of dengue include fluid leak, bleeding, hepatitis, encephalopathy, ARDS especially in paediatric age group and its most important public health problem in tropical developing countries and also have a major economic and social impact. The studies on dengue in paediatric age group are scant in this part of the country. Hence this study was taken up with aim of analysing the clinical and haematological and radiological parameters in children during the febrile phase of dengue and correlating them with onset of complications. This may provide us with guidelines for early recognition of children with dengue who are at risk of developing complications, thus reducing morbidity and mortality and providing timely intervention [8].

\section{Methodology}

A cross sectional study was undertaken in the Department of Paediatrics of Medical College and Hospital, among 250 cases presenting with fever for 2 to 7 days from the outpatient and inpatients departments over period of 20 months. An informed Bilingual and written consent was obtained from the close patient relatives before the study was started. The calculated sample size was 250 cases and calculated as follows,

According to study done by Sharma RS et al., the Attack rate of dengue fever during Epidemics is between $40-50 \%$. The endemicity of the disease is around $30 \%$.

$$
\mathrm{N}=4 \mathrm{Z} \alpha^{2} \mathrm{pq}
$$

$\mathrm{p}=$ Attack rate of dengue in endemic areas $(30 \%)$

$\mathrm{q}=100-\mathrm{p}$

$\mathrm{Z} \alpha=1.96$

$\alpha=0.05$

$\partial=$ the percentage of error $(20 \%$ of $30 \%$ attack rate)

The calculated sample size is 224 cases which was approximately equal to 250 cases.

\section{Inclusion criteria}

- Serologically confirmed (positive for NS1 antigen or IgM or both) dengue fever patients, admitted at Medical College Hospital and Research Centre.

- Those patients whose parents give informed consent.

- All cases in pediatric age group of both sex

\section{Exclusion criteria}

- Clinical features of dengue with NS 1 negative and IgM negative.

- $\quad$ IgG positive cases with features of dengue.

- Lost for study (referred during the course of treatment or Discharge against medical advice.

\section{Results}

Table 1: Distribution of the study group according to age group

\begin{tabular}{|c|c|c|}
\hline Age group & Frequency & Percent \\
\hline Less than 3 years & 47 & 19.0 \\
\hline $3-6$ years & 38 & 15.2 \\
\hline $6-9$ years & 56 & 22.4 \\
\hline $9-12$ years & 45 & 18.0 \\
\hline 12-15 years & 44 & 17.6 \\
\hline More than 15 years & 20 & 8.0 \\
\hline Total & 250 & 100 \\
\hline
\end{tabular}

This study had shown that, about $22.4 \%$ of the study group were aged between $6-9$ years, $19 \%$ were aged less than 3 years, $18 \%$ were aged between $9-12$ years, $17.6 \%$ were aged between $12-15$ years.

Table 2: Distribution of the study group according to sex

\begin{tabular}{|c|c|c|}
\hline Sex & Frequency & Percent \\
\hline Male & 143 & 57.2 \\
\hline Females & 107 & 42.8 \\
\hline Total & 250 & 100 \\
\hline
\end{tabular}

Male patients outnumbered females in this study.

Table 3: Distribution of the study group according to symptoms

\begin{tabular}{|c|c|c|}
\hline Symptoms & Frequency & Percent \\
\hline Fever & 250 & 100.0 \\
\hline Cold & 133 & 53.2 \\
\hline Cough & 79 & 31.6 \\
\hline Conjunctival congestion & 47 & 18.8 \\
\hline Lymphadenopathy & 17 & 6.8 \\
\hline Skin rash & 79 & 31.6 \\
\hline Face flushing & 35 & 14.0 \\
\hline Vomiting & 64 & 25.6 \\
\hline Loose stool & 46 & 18.4 \\
\hline Decreased urine output & 47 & 18.8 \\
\hline Pain abdomen & 122 & 48.8 \\
\hline Headache & 43 & 17.2 \\
\hline Retro orbital pain & 12 & 4.8 \\
\hline Myalgia/ Arthralgia & 53 & 21.2 \\
\hline Bleeding tendency & 62 & 24.8 \\
\hline Similar illness in family & 10 & 4.0 \\
\hline
\end{tabular}

All the patients in this study had fever, $53.2 \%$ had cold, $48.8 \%$ had pain abdomen, $31.6 \%$ had skin rash and cough and $24.8 \%$ had bleeding tendency.

Table 4: Distribution of the study group according to signs

\begin{tabular}{|c|c|c|}
\hline Signs & Frequency & Percent \\
\hline Tachycardia & 2 & 0.8 \\
\hline Raised Respiratory rate & 1 & 0.4 \\
\hline Positive tourniquet test & 24 & 9.6 \\
\hline Reduced blood pressure & 1 & 0.4 \\
\hline Hepatomegaly & 159 & 63.6 \\
\hline
\end{tabular}


Hepatomegaly in $63.6 \%$ of the cases followed by positive tourniquet test in $9.6 \%$ of the cases and raised total count in $6 \%$ of the cases.

Table 5: Distribution of the study group according to Leucopenia and complications

\begin{tabular}{|c|c|c|c|}
\hline \multirow{2}{*}{ Leucopenia } & \multicolumn{2}{|c|}{ Complications } & \multirow{2}{*}{ Total n (\%) } \\
\cline { 2 - 3 } & No n (\%) & Yes n (\%) & \\
\hline No & $51(22.9)$ & $13(48.1)$ & $64(25.6)$ \\
\hline Yes & $172(77.1)$ & $14(51.9)$ & $186(74.4)$ \\
\hline Total & $223(100)$ & $27(100)$ & $250(100)$ \\
\hline
\end{tabular}

$\chi^{2}$ Value $=8.08 \mathrm{df}=1 \mathrm{P}$ value, $\mathrm{Sig}=0.004, \mathrm{Sig}$

Leucopenia was observed in $77.1 \%$ of the patients without complications and $51.9 \%$ of the patients with complications which was statistically significant.

Table 6: Distribution of the study group according to Platelet count and complications

\begin{tabular}{|c|c|c|c|}
\hline \multirow{2}{*}{ Platelet count } & \multicolumn{2}{|c|}{ Complications } & \multirow{2}{*}{ Total n (\%) } \\
\cline { 2 - 3 } & No n (\%) & Yes n (\%) & \\
\hline Normal & $66(29.6)$ & 0 & $66(26.4)$ \\
\hline Decreased & $157(70.4)$ & $27(100)$ & $184(73.6)$ \\
\hline Total & $223(100)$ & $27(100)$ & $250(100)$ \\
\hline
\end{tabular}

$\chi 2$ Value $=10.857 \mathrm{df}=1 \mathrm{P}$ value, Sig= 0.001, Sig

The platelet count was decreased in $70.4 \%$ of the patients without complications and all the patients with complications. There was a statistically significant difference in the platelet count between the patients without and with complications.

Table 7: Distribution of the study group according to NS1 test and complications

\begin{tabular}{|c|c|c|c|}
\hline \multirow{2}{*}{ NS1 test } & \multicolumn{2}{|c|}{ Complications } & \multirow{2}{*}{ Total n (\%) } \\
\cline { 2 - 3 } & No n (\%) & Yes n (\%) & \\
\hline Negative & $65(29.1)$ & $1(3.7)$ & $66(26.4)$ \\
\hline Positive & $158(70.9)$ & $26(96.3)$ & $184(73.6)$ \\
\hline Total & $223(100)$ & $27(100)$ & $250(100)$ \\
\hline
\end{tabular}

$\chi^{2}$ Value $=8.8025 \mathrm{df}=1 \mathrm{P}$ value, $\mathrm{Sig}=0.005$, Sig

NS1 test was positive in $70.9 \%$ of the patients without complications and $96.3 \%$ of the cases with complications. There was a statistically significant difference in the NS1 test in patients without and with complications.

Table 8: Distribution of the study group according to IgM test and complications

\begin{tabular}{|c|c|c|c|}
\hline \multirow{2}{*}{ IgM } & \multicolumn{2}{|c|}{ Complications } & \multirow{2}{*}{ Total n (\%) } \\
\cline { 2 - 3 } & No n (\%) & Yes n (\%) & \\
\hline Negative & $142(63.7)$ & $16(59.3)$ & $158(63.2)$ \\
\hline Positive & $81(36.3)$ & $11(40.7)$ & $92(36.8)$ \\
\hline Total & $223(100)$ & $27(100)$ & $250(100)$ \\
\hline
\end{tabular}

$\chi 2$ Value $=0.202 \mathrm{df}=1 \mathrm{P}$ value, $\mathrm{Sig}=0.653, \mathrm{NS}$

The IgM test was positive in $36.3 \%$ of the patients without complications and $40.7 \%$ of the patients with complications. This difference was not statistically significant between the patients without and with complications.
Table 9: Distribution of the study group according to IgG test and complications

\begin{tabular}{|c|c|c|c|c|}
\hline \multirow{2}{*}{ IgG } & & Complications & \multicolumn{2}{|c|}{ Total n (\%) } \\
\cline { 2 - 5 } & No n (\%) & Yes n (\%) & \multicolumn{2}{|c|}{} \\
\hline Negative & $212(95.1)$ & $26(96.3)$ & 238 & $(95.2)$ \\
\hline Positive & $11(4.9)$ & $1(3.7)$ & 12 & $(4.8)$ \\
\hline Total & $223(100)$ & $27(100)$ & \multicolumn{2}{|c}{$250(100)$} \\
\hline
\end{tabular}

$\chi^{2}$ Value $=0.08 \mathrm{df}=1 \mathrm{P}$ value, $\mathrm{Sig}=0.778, \mathrm{NS}$

The IgG test was positive in $4.9 \%$ of the cases without and $3.7 \%$ of the cases with complications. There was no statistically significant difference in $\operatorname{IgG}$ between the patients without and with complications.

Table 10: Distribution of the study group according to C3 levels and complications

\begin{tabular}{|c|c|c|c|c|}
\hline $\mathrm{C3}$ & \multicolumn{3}{|c|}{ Complications } & Total \\
\hline & No n (\%) & \multicolumn{2}{|c|}{ Yes n (\%) } & n (\%) \\
\hline Normal & $197(88.3)$ & 25 & $(92.6)$ & $22(88.8)$ \\
\hline Abnormal & $26(11.7)$ & \multicolumn{2}{|c|}{$2(7.4)$} & $28(11.2)$ \\
\hline Total & $223(100)$ & 27 & (100) & $250(100)$ \\
\hline
\end{tabular}

$\chi 2$ Value $=0.438 \mathrm{df}=1 \mathrm{P}$ value, $\mathrm{Sig}=0.508, \mathrm{NS}$

The C3 level was abnormal in $11.7 \%$ of the cases without complications and $7.4 \%$ of the cases with complications. This difference in C3 levels was not statistically significant between the patients without and with complications.

Table 11: Widal test and complications

\begin{tabular}{|c|c|c|c|}
\hline \multirow{2}{*}{ Widal test } & \multicolumn{2}{|c|}{ Complications } & \multirow{2}{*}{ Total n (\%) } \\
\cline { 2 - 3 } & No n (\%) & Yes n (\%) & \\
\hline Negative & $81(36.3)$ & $22(81.5)$ & $103(41.2)$ \\
\hline Positive & $142(63.7)$ & $5(18.5)$ & $147(58.8)$ \\
\hline Total & $223(100)$ & $27(100)$ & $250(100)$ \\
\hline
\end{tabular}

$\chi 2$ Value $=20.274 \mathrm{df}=1 \mathrm{P}$ value, $\mathrm{Sig}=0.000, \mathrm{Sig}$

The Widal test was positive in $63.7 \%$ of the cases without and $18.5 \%$ with complications. This difference in Widal test was statistically significant between the patients without and with complications.

\section{Discussion}

About $22.4 \%$ of the study group were aged between $6-9$ years and $19 \%$ were aged less than 3 years. A study by Dhobale et al. had shown that, about $39 \%$ of the children belonged to $5-10$ years. Among them, $35.9 \%$ were females and $64.1 \%$ were males ${ }^{[9]}$. A study by Gupta et al. had shown that the mean age was 11.6 years ${ }^{[10]}$. A study by Tamil Selvan et al. had reported that, about 35.5 ere aged between 6-10 years ${ }^{[11]}$. A study by Shinde et al. had shown that, the mean age was 8.7 years ${ }^{[12]}$. In a study by Banerjee et al., most of the cases were school age children ${ }^{[13]}$.

Male patients outnumbered females in this study. In a study by Dhobale et al., about $72 \%$ were females and $28 \%$ were males ${ }^{[9]}$. A study by Gupta et al. had reported that males outnumbered females ${ }^{[10]}$. A study by Shinde et al. had shown that males were than females ${ }^{[12]}$. A study by Banerjee et al. had shown that about $58 \%$ of the cases were males ${ }^{[13]}$. 
All the patients in this study had fever, $53.2 \%$ had cold and $48.8 \%$ had pain abdomen. About $93 \%$ of the cases had fever followed by abdominal pain (43\%), vomiting (37\%) and Bodyache $(15 \%)$ of the cases. A study by Gupta et al. had shown that, $99.2 \%$ of the cases had fever and the mean duration of the fever was 5 days. About $23.1 \%$ of the cases had Petechia, $44.5 \%$ had spontaneous bleeding, $18.2 \%$ had malena, 9.3\% had Hematomesis, $12 \%$ had epistaxis, $1.2 \%$ had Hematuria, 3.7\% had gum bleeding and $20.5 \%$ had rash ${ }^{[10]}$. A study by Tamil Selvan et al. had shown that, about 2.5\% had epistaxis, $1.8 \%$ had Petechiae/ Purpura, $0.72 \%$ had Malaena $0.72 \%$ and $0.72 \%$ had Subconjuctival hemorrhage ${ }^{[11]}$. A study by Shinde et al. had shown that, the fever was present in all cases and abdominal pain, vomiting, retroorbital pain, vomiting, retroorbital pain and abdominal distension were seen commonly ${ }^{[12]}$. A study by Banerjee et al. had shown that, $63 \%$ had myalgia and arthealgia, $55.5 \%$ had headache, $29 \%$ presented with gastrointestinal infections, $25.5 \%$ had rash, $13 \%$ had hemorrhagic manifestations ${ }^{[13]}$. Hepatomegaly in $63.6 \%$ of the cases followed by positive tourniquet test in $9.6 \%$ of the cases and raised total count in $6 \%$ of the cases. A study by Dhobale et al. had shown that, $11 \%$ had hepatosplenomegaly ${ }^{[9]}$. In a study by Gupta et al., 33.3\% had hepatomegaly ${ }^{[10]}$.

Leucopenia was observed in $77.1 \%$ of the patients without complications and $51.9 \%$ of the patients with complications which was statistically significant. In a study by Dhobale et al., $29 \%$ of the cases had leucopenia ${ }^{[9]}$. In a study by Gupta et al. had shown that, the mean WBC count in the study group was $6300^{[10]}$.

The platelet count was decreased in $70.4 \%$ of the patients without complications and all the patients with complications. There was a statistically significant difference in the platelet count between the patients without and with complications. A study by Dhobale et al. had shown that about $46 \%$ of the cases had normal TLC ${ }^{\text {[9] }}$. In a study by Gupta et al. had shown that the mean platelet count had 50 thousand ${ }^{[10]}$. A study by Tamil Selvan et al. had shown that, majority of the cases had moderate thrombocytopenia ${ }^{[11]}$. A study by Shinde et al. had shown that $40 \%$ had platelet count between 51,000 and 1 lakh. Majority of the cases with severe thrombocytopenia presented with DF with or without warning signs ${ }^{[12]}$.

NS1 test was positive in $70.9 \%$ of the patients without complications and $96.3 \%$ of the cases with complications. A study by Dhobale et al. had shown that, $20 \%$ had $\mathrm{NS}_{1}$ antigen positive ${ }^{[9]}$. About $39 \%$ had NS1 positive in a study by Shinde et al. ${ }^{[12]}$.

The IgM test was positive in $36.3 \%$ of the patients without complications and $40.7 \%$ of the patients with complications. In a study by Dhobale et al., $31 \%$ of the cases were $\operatorname{IgM}$ positive ${ }^{[9]}$. A study by Shinde et al. had shown that $19 \%$ were $\operatorname{IgM}$ positive. About $2 \%$ had both $\operatorname{IgM}$ and NS1 was positive ${ }^{[12]}$. The IgG test was positive in $4.9 \%$ of the cases without and $3.7 \%$ of the cases with complications. A study by Dhobale et al. had shown that, $23 \%$ had IgG positive ${ }^{[9]}$. A study by Shinde et al. had shown that 2 persons were $\mathrm{IgG}$ positive. About $\operatorname{IgM} \& \operatorname{IgG}$ was positive $3 \%$ of the cases ${ }^{[12]}$. The C3 level was abnormal (decreased) in $11.7 \%$ of the cases without complications and $7.4 \%$ of the cases with complications. No studies have compared these findings.

The widal test was positive in $63.7 \%$ of the cases without and $18.5 \%$ with complications. These results were not compared any other studies.

\section{Conclusion}

This study had shown that, the age group was between $6-9$ years, males sex, fever was the common sign, hepatomegaly was the common sign, leucopenia, reduced platelet count, NS1 positive, $\operatorname{IgM}$ and $\operatorname{IgG}$ positive, normal C3 count, positive widal test was present in $11.1 \%$ of the cases.

\section{References}

1. San Martín JL, Brathwaite O, Zambrano B, Solórzano JO, Bouckenooghe A, Dayan GH et al., The epidemiology of Dengue in the Americas over the last three decades: A worrisome reality, Am J Trop. Med. Hyg. 2010; 82(1):128-135.

2. Tanner L, Schreiber M, Low JGH, Ong A, Tolfvenstam T, Cameroon P et al. Decision Tree Algorithms Predict the Diagnosis and Outcome of Dengue Fever in the Early Phase of Illness. Journal of Trop Dis. 2008; 2(3):196-201.

3. Butt N, Abbasi A, Munir SM, Masroor Ahmad S, Sheikh QH. Hematological and Biochemical indicators for early diagnosis of Dengue viral infection. Journal of the college of Physicians and Surgeons Pakistan. 2008; 18(5):282-285.

4. Venkata Sai PM, Krishnan R. Role of ultrasound in Dengue fever. The British Journal of Radiology. 2005; 78:416-418.

5. World Health Organization. The world health report: fighting disease - fostering development. Geneva: WHO, 1996, 137.

6. Gratz NG, Knudsen AB. The rise and spread of dengue, dengue haemorrhagic fever and its vectors: a historical review (up to 1995). Geneva: World Health Organization. 1996; (CTD/FIL (DEN) 96(7):71.

7. Gubler DJ. Dengue and dengue haemorrhagic fever: its history and resurgence as a global public health problem. In: Gulber DJ, Kuno G, editors. Dengue and dengue haemorrhagic fever. Wallingford, Oxon: CAB international, 1997, 1-22.

8. Pinheiro FP, Corber SJ. Global situation of dengue and dengue haemorrhagic fever and its emergence in the Americas, World Health Stat Q. 1997; 50:161-8.

9. Dhobale RV, Gore AD, Waghacha-vare VB, Kumbhar SG, Kadam YR, Dhumale GB. Clinical and Labora-tory Characteristics of Pediatric Dengue Fever Patients in a Ter-tiary Care Hospital. Ntl J Community Med. 2015; 7(1):21-24.

10. Gupta V, Yadav TP, Pandey RM et al. Risk factors of dengue shock syndrome in children, J Trop Ped. 2011; 57(6):451-6.

11. Tamil Selvan, D’Souza JLP, Swamy N, Kumar M, Prevalence and severity of Thrombocyopenia in Dengue fever in children, Sch. J App. Med. Sci., August. 2015; 3(5D):2068-2070.

12. Zoraida I Velasco-Salas, Gloria M Sierra, Diamelis M Guzma' N, Julio Zambrano, Daniel Vivas, Guillermo Comach. Wilschut, and Adriana Tami. Dengue

13. Seroprevalence and Risk Factors for Past and Recent Viral Transmission in Venezuela: A Comprehensive Community-Based Study. Am. J Trop. Med. Hyg. 2014; 91(5):1039-48.

14. Shah I, Deshpande GC, Tardeja PN. Outbreak of dengue in Mumbai and predictive markers for dengue shock syndrome. J Trop Pediatr. 2004; 50(5):301-5. 